\title{
Estudo preliminar da atividade antibacteriana das cascas de Erythrina velutina Willd., Fabaceae (Leguminosae)
}

\author{
S. Virtuoso, A. Davet, J.FG. Dias, M.M. Cunico, M.D. Miguel, A.B. Oliveira, \\ O.G. Miguel $^{*}$
}

Departamento de Farmácia, Laboratório de Fitoquímica, Universidade Federal do Paraná, Av. Prefeito Lothário Meissner 3400, 80210-170, Jardim Botânico, Curitiba, PR, Brasil

RESUMO: A Erythrina velutina é popularmente conhecida como suinã, mulungu, corticeira, mulungu-da-catinga dentre outros. Das várias espécies distribuídas pelo mundo cerca de doze estão no Brasil. A casca é utilizada, principalmente no nordeste brasileiro, pelas propriedades sudorífica, calmante, emoliente, peitoral, anestésica local e outras. Considerando-se que não existem estudos sobre o potencial microbiológico das cascas de Erythrina velutina este trabalho teve por objetivo avaliá-lo preliminarmente contra oito bactérias patogênicas. Foram utilizados os métodos de difusão em disco e concentração inibitória mínima para o extrato etanólico bruto e difusão em disco para a fração hexano. A atividade contra o Staphylococcus aureus e Streptococcus pyogenes foi evidenciada para ambas as amostras. A viabilidade de futuras pesquisas com outras frações e substâncias isoladas na busca de novas alternativas, visando uma terapêutica racional a partir de fontes naturais foi apontada pelos resultados.

Unitermos: Erythrina velutina, Fabaceae, atividade antibacteriana.

\begin{abstract}
Preliminary study of the antibacterial activity of Erythrina velutina Willd. Fabaceae (Leguminosae) bark”. Erythrina velutina is popularly known as suinã, mulungu, corticeira, mulungu-da-catinga among others. Of the several species spread around the world about twelve are found in Brazil. Mainly in the Brazilian northeast the bark is used due to its sudorific, sedative, emollient, pectoral and topical anesthetic properties. Considering that there are no studies about the antibacterial potential of Erythrina velutina, this research aimed at evaluating, at least preliminarily, bark activity against eight pathogenic bacteria. The crude ethanol extract was tested by the disk diffusion method and minimal inhibitory concentration (MIC) and the hexane fraction by the disk diffusion method. Both samples demonstrated activity against Staphylococcus aureus and Streptococcus pyogenes. The results pointed to the viability of future research on other fractions and substances isolated from Erythrina velutina in search for new rational therapeutic alternatives based on natural sources.
\end{abstract}

Keywords: Erythrina velutina, Fabaceae, antibacterial activity.

\section{INTRODUÇÃO}

A partir do século XIX a humanidade se deparou perplexa diante do diverso e inesgotável arsenal terapêutico presente nas plantas medicinais devido a descoberta de substâncias ativas, que em estado natural ou após sofrerem processos de transformação química, possuem atividade biológica, muitas vezes já confirmadas pelo uso popular e comprovadas cientificamente (Miguel; Miguel, 2004).

O gênero Erythrina (família Fabaceae) ocorre nas regiões tropicais e sub-tropicais do mundo. Possui cerca de 110 espécies, das quais 70 são nativas da América (EPAMIG, 1993; Vasconcelos et al., 2003). O nome Erythrina, do grego "erythros", significa "vermelho" em alusão à cor de suas flores. São empregadas como ornamentais e sombreadoras das lavouras de café e cacau (EPAMIG, 1993).

Erythrina velutina Willd. (Fabaceae) é popularmente conhecida como suinã, mulungu, canivete, corticeira, mulungu-da-catinga, pau-de-coral, sanaduí, sananduva, dentre outros (Lorenzi, 1992; EPAMIG, 1993). É uma espécie nativa da flora brasileira que tem sido utilizada na medicina popular em algumas regiões do nordeste brasileiro.

São atribuídas às preparações da casca propriedades sudorífica, calmante, emoliente, peitoral e do seu fruto seco ação anestésica local que é usado na forma de cigarro como odontálgico, embora a eficácia e segurança de seu uso ainda não tenham sido confirmadas cientificamente (Lorenzi; Matos, 2002). Este fato torna imperioso o investimento na pesquisa fitoquímica e biológica a fim de se comprovar seu potencial terapêutico. Por meio de estudos farmacológicos empregando-se o extrato da E. velutina foram demonstrados os seus efeitos periféricos e sobre o sistema nervoso central. Dantas et al. (2004) evidenciaram que o extrato aquoso das folhas de E. velutina em baixas doses interferiu em processos 
mnemônicos e em doses maiores agiu como sedativo e bloqueador neuromuscular periférico.

As plantas do gênero Erythrina são conhecidas por produzirem alcalóides, flavonóides e isoflavonóides. Estas plantas representam a principal fonte de alcalóides tetracíclicos, sendo que estes possuem atividade semelhante ao curare causando paralisia muscular (Amer et al., 1991; Decker et al., 1995).

Por meio do fracionamento em coluna cromatográfica da fração acetato de etila obtida das cascas de $E$. velutina foram isolados a erivelutinona (2',4'-dihidroxi-6-prenil-7-metoxiisoflavanona) de aspecto viscoso e coloração marrom-amarelado e a 3'O-metilsigmoidina (Da Cunha et al., 1996), também a faseolidina e homohesperetina, sendo que a última ainda não havia sido isolada de uma planta da família Fabaceae (Rabelo et al., 2001).

Além disto, este gênero tem provado ser uma fonte farta de espécies contendo agentes antimicrobianos que pertencem a várias classes estruturais de flavonóides, como por exemplo, a E. variegata cuja atividade do extrato bruto das raízes foi demonstrada para Staphyloccus aureus e Mycobacterium smegmatis (Telikepalli et al., 1990).

Atividades com interesse farmacêutico foram apresentadas também por outros representantes do gênero como a $E$. speciosa que no Brasil é utilizada como analgésica, anti-inflamatória e bactericida (Dias Filho et al., 2002).

Considerando-se que não há estudos sobre o potencial microbiológico da E. velutina e que as pesquisas sobre a atividade antimicrobiana de plantas representam um grande desafio para a descoberta e identificação de fármacos (Cunico et al., 2003), este trabalho teve por objetivo avaliar preliminarmente o potencial de atividade antibacteriana do extrato etanólico bruto e fração hexano das cascas da espécie.

\section{MATERIAL E MÉTODOS}

\section{Material}

Os solventes utilizados para todos os procedimentos apresentavam grau de pureza analítico (Merck®). As suspensões bacterianas foram diluídas em salina estéril e padronizadas pela turbidez conforme o tubo 0,5 da escala de MacFarland (0,5 mL de $\mathrm{BaCl}_{2} \cdot 2 \mathrm{H}_{2} \mathrm{O}$ $0,048 \mathrm{M}-1,75 \%$ peso/volume em $99,5 \mathrm{~mL}$ de $\mathrm{H}_{2} \mathrm{SO}_{4} 0,36$ $\mathrm{N}-1 \%$ volume/volume). As culturas puras das bactérias (ATCC - American Type Culture Collection) e os discos de antibióticos usados como controle, cloranfenicol e cefalotina, foramadquiridoscomercialmente(Newprov $®$ ). Os meios de cultura utilizados foram ágar Muller-Hinton para difusão em disco e caldo caseína de soja (CASOY) para o teste de concentração inibitória mínima - CIM. O etanol utilizado nos testes antibacterianos foi o mesmo da extração.

\section{Material vegetal}

As cascas de E. velutina Willd., (Fabaceae) foram coletadas na cidade de Petrolina, Pernambuco em janeiro de 2003 e em seguida, foram secas e estabilizadas pela EMBRAPA Semi-Árido e a exsicata de identificação está registrada sob número 2298 no Museu Botânico da mesma instituição.

\section{Preparo do extrato bruto}

As cascas secas, estabilizadas e moídas em total de 2,960 kg, foram submetidas a extração com etanol $96^{\circ}$ GL em soxhlet até esgotamento. O material obtido foi concentrado em evaporador rotatório sob pressão reduzida $\left(50{ }^{\circ} \mathrm{C}\right)$ para aproximadamente $1 / 5$ do seu volume. Este volume foi conservado em freezer por 24 horas, em frasco âmbar, visando a precipitação de substâncias com aparência de goma e os pigmentos. Após esse período o extrato foi filtrado a vácuo em funil de Büchner e obtevese $200 \mathrm{~mL}$ (aproximadamente 71,2 g) de extrato etanólico bruto (EB). O resíduo seco do EB foi determinado conforme preconizado pela Farmacopéia Brasileira IV edição (1988) pesando-se 1,0 mL (medida volumétrica) do material em triplicata, e submetendo as amostras a 105 ${ }^{\circ} \mathrm{C}$ até peso constante após resfriamento em dessecador, obteve-se $312,75 \mathrm{mg} / \mathrm{mL}$ o que corresponde a 3,67 \% (peso/peso) em relação a massa inicial das cascas.

\section{Preparo da frações}

Uma amostra do EB foi submetida a fracionamento líquido-líquido em aparelho de soxhlet modificado (Carvalho, 2001) com solventes de polaridade crescente: hexano, diclorometano e acetato de etila gerando as frações hexano (FHEX), fração diclorometano (FDMT), fração acetato de etila (FATE) e o restante foi denominado fração hidroalcóolica remanescente (FHAR).

Para este estudo foi utilizada somente a fração hexano padronizada a $200 \mathrm{mg} / \mathrm{mL}$.

\section{Cromatografia gasosa da fração hexano}

Uma amostra da FHEX solubilizada em metanol foi analisada por cromatografia gasosa conforme método de Padronização Interna de Carvalho (2001) com a finalidade de caracterizar e quantificar os analítos voláteis por Retenção Relativa em relação ao acetato de tocoferol. Utilizou-se cromatográfo gasoso equipado com colunas megabore DB-1 (100\% dimetilpolisiloxano, polaridade 5) e DB-17 (50\% fenil e 50\% dimetilpolisiloxano, polaridade 24) de $0,53 \mathrm{~mm}$ de diâmetro interno por 30 m de comprimento. Utilizou-se como gás de arraste hidrogênio a $6 \mathrm{~mL}$ por minuto, split a $6 \mathrm{~mL}$ por minuto (razão 1:1), purga do septo $3 \mathrm{~mL}$ por minuto, make up nitrogênio $25 \mathrm{~mL}$ por minuto e oxigênio a $100 \mathrm{~mL}$ 
por minuto. O gradiente de temperatura utilizado foi: temperatura inicial $100^{\circ} \mathrm{C}$ com patamar de 1 minuto e rampa de aquecimento a $7^{\circ} \mathrm{C}$ por minuto até $260{ }^{\circ} \mathrm{C}$ com patamar de 66 minutos. A temperatura do injetor foi de $260{ }^{\circ} \mathrm{C}$ e do detector foi de $280^{\circ} \mathrm{C}$. O volume de injeção foi de $2 \mu \mathrm{L}$.

\section{Avaliação da atividade antibacteriana}

Para a realização do ensaio foram utilizados dois métodos: difusão em ágar adaptado por Romeiro (2001) para o extrato etanólico bruto e fração hexano, e Concentração Inibitória Mínima (CIM), segundo Konemann et al. (1993) para o extrato bruto. Foram utilizadas as seguintes bactérias em ambos os testes: Staphylococcus aureus (ATCC 6538); Streptococcus pyogenes (ATCC 19615); Staphylococcus epidermidis (ATCC 12228); Proteus mirabilis (ATCC 43071); Pseudomonas aeruginosa (ATCC 27283); Klebsiella pneumoniae (ATCC 13883); Escherichia coli (ATCC 11229); Salmonella typhimurium (ATCC 14028).

\section{Teste de difusão em ágar}

Discos estéreis de papel de 6 mm de diâmetro foram impregnados com $10 \mu \mathrm{L}$ do EB e da FHEX nas concentrações de $100 \%$, 50\%, 25\% e 12,5\% conforme mostra a Tabela 1. As diluições foram feitas em etanol $96^{\circ} \mathrm{GL}$ e os testes realizados em triplicata.

Como padrões de inibição de crescimento foram utilizados dois discos de antibióticos comerciais, o cloranfenicol $30 \mu \mathrm{g}$ e cefalotina $30 \mu \mathrm{g}$.

Os discos contendo a amostra em estudo foram secos a $40{ }^{\circ} \mathrm{C}$ e distribuídos nas placas de Petri contendo meio ágar Mueller-Hinton, onde foram inoculadas as bactérias em solução padronizada segundo o tubo 0,5 da escala de MacFarland. Em cada placa de teste foram colocados um disco de cada diluição, um disco com etanol 96 $6^{\circ} \mathrm{GL}$ (controle) e um com o padrão de cloranfenicol, totalizando seis discos por placa. Foram feitas placascontrole com os dois padrões de antibióticos e o controle com etanol $96^{\circ} \mathrm{GL}$ para cada microrganismo. As placas foram incubadas em estufa a $35^{\circ} \mathrm{C}$ e os resultados foram lidos após 24 horas.

\section{Concentração inibitória mínima (CIM)}

Este teste foi realizado com o EB. As bactérias em suspensão na concentração padronizada pelo tubo

Tabela 1. Concentrações de EB e FHEX nos resíduos secos e discos

\begin{tabular}{c|c|c|c|c}
\hline \multirow{2}{*}{ Concentração } & \multicolumn{2}{|c|}{ EB } & \multicolumn{2}{c}{ FHEX } \\
\cline { 2 - 5 } & $\begin{array}{c}\text { Resíduo seco em } \\
\mathrm{mg} / \mathrm{mL}\end{array}$ & $\begin{array}{c}\text { Sólidos em } \\
\mathrm{mg} / 10 \mu \mathrm{l}\end{array}$ & $\begin{array}{c}\text { Resíduo seco em } \\
\mathrm{mg} / \mathrm{mL}\end{array}$ & $\begin{array}{c}\text { Sólidos em } \\
\mathrm{mg} / 10 \mu \mathrm{l}\end{array}$ \\
\hline $100,0 \%$ & 312,75 & $312,75 \times 10^{-2}$ & 200 & $200 \times 10^{-2}$ \\
$50,0 \%$ & 156,37 & $156,37 \times 10^{-2}$ & 100 & $100 \times 10^{-2}$ \\
$25,0 \%$ & 78,19 & $78,19 \times 10^{-2}$ & 50 & $50 \times 10^{-2}$ \\
$12,5 \%$ & 39,10 & $39,10 \times 10^{-2}$ & 25 & $25 \times 10^{-2}$ \\
\hline
\end{tabular}

Tabela 2. Dados de comparação da fração hexano com os padrões de metabólicos

\begin{tabular}{lcc|c|c|c}
\hline \multicolumn{1}{c|}{ Referência } & tr & RR & FHEX & RR & tr \\
\hline Ácido fênico & 3.464 & 0.060 & Ponto 2 & 0,061 & 2.690 \\
Ácido cinâmico & 12.315 & 0.214 & Ponto 14 & 0,213 & 9.415 \\
Acetato de tocoferol & 57.629 & 1.000 & - & - & - \\
Alfa amirina & 64.964 & 1.130 & Ponto 73 & 1,135 & 50.085 \\
Estigmasterol & 67.204 & 1.170 & Ponto 74 & 1,170 & 51.605 \\
Beta amirina & 71.064 & 1.230 & Ponto 75 & 1,237 & 54.581 \\
Beta sitosterol & 73.261 & 1.270 & Ponto 72 & 1,273 & 49.098 \\
Lupeol & 82.729 & 1.440 & Ponto 82 & 1,457 & 64.278 \\
\hline
\end{tabular}

Legenda: $\mathrm{tr}$ = tempo de retenção; $\mathrm{RR}$ = retenção relativa; 


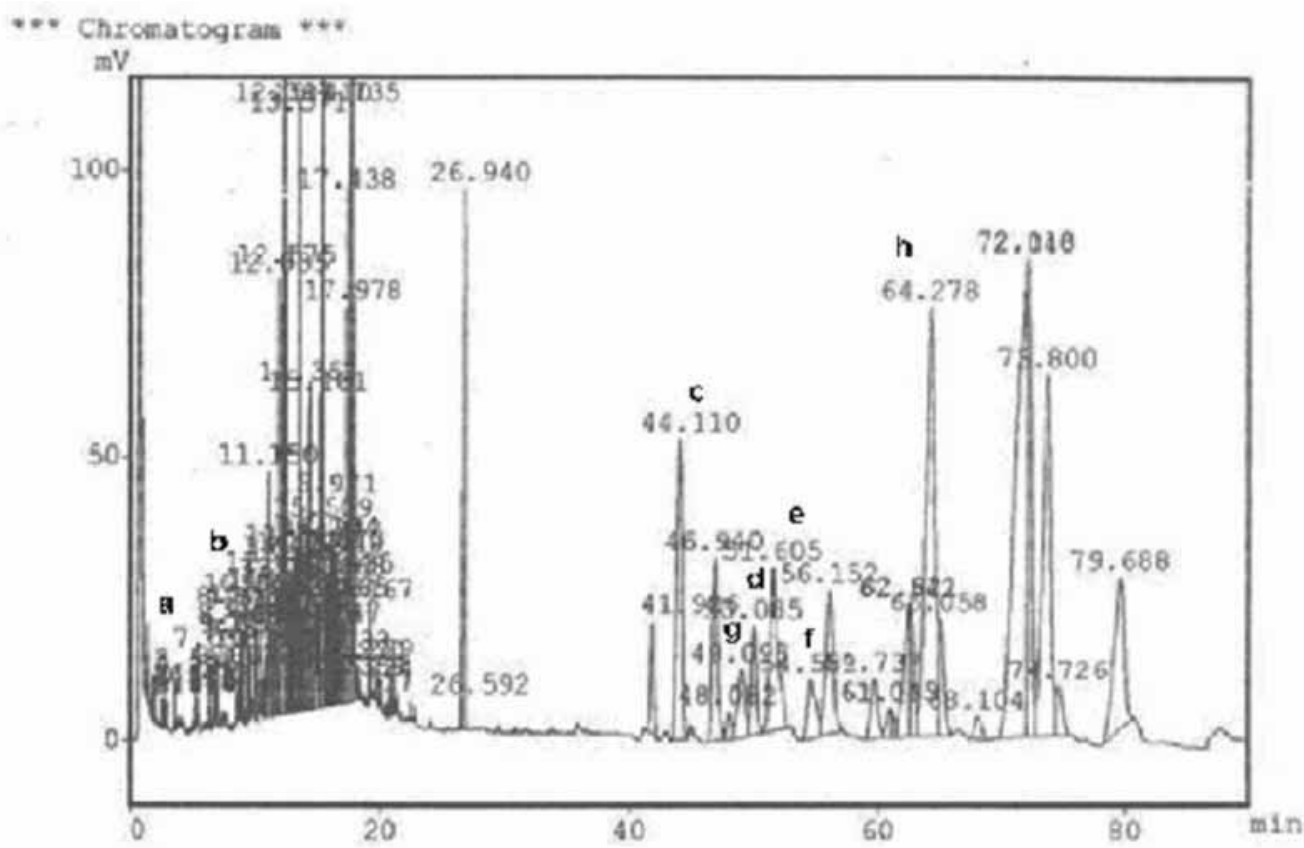

Figura 1. Cromatograma da fração hexano (FHEX).

Legenda: a - ácido fênico; b - ácido cinâmico; c - acetato de tocoferol; d - $\alpha$-amirina; e - estigmasterol; f

- $\beta$-amirina; g - $\beta$-sitosterol; $\mathrm{h}$ - lupeol.

0,5 da escala de MacFarland foram diluídas em solução estéril de Tween 80 a 0,2\% em proporção de 2:100 e inoculadas em caldo tríptico caseína de soja - CASOY. As concentrações decrescentes de extrato utilizadas para o teste, partindo-se de 312,75 mg/mL foram 1:1 (156,37 $\mathrm{mg} / \mathrm{mL}), 1: 2(78,19 \mathrm{mg} / \mathrm{mL}), 1: 4(39,10 \mathrm{mg} / \mathrm{mL}), 1: 8$ (19,55 mg/mL), 1:16 (9,77 mg/mL), 1:32 (4,89 mg/mL) e 1:64 (2,44 mg/mL). O teste foi realizado em triplicata.

Como controle positivo foi preparado tubo com 1,0 mL de suspensão de bactérias e 1,0 mL de caldo nutritivo a fim de se confirmar o crescimento viável dos microrganismo durante o teste; o controle negativo foi o extrato diluído em caldo nutritivo na concentração 1:1, sem o inóculo de microrganismos visando evitar erros de leitura associados a turbidez do extrato no meio.

\section{RESULTADOS}

A análise do cromatograma da amostra FHEX obtido no cromatógrafo a gás (CG) foi efetuada por comparação com o cromatograma padrão de referências analisadas em CG por padronização interna segundo Carvalho (2001). Através desta foi evidenciada a presença de ácido fênico, ácido cinâmico, $\alpha$-amirina, estigmasterol, $\beta$-amirina, $\beta$-sitosterol e lupeol, conforme figura 1 e tabela 2. A comparação baseia-se na Retenção Relativa (RR) das substâncias no cromatógrafo, com margem de 1 por cento (1\%) entre os valores. Estas substâncias ainda não haviam sido relatadas na espécie em estudo.

Os resultados, expressos em média, para os controles e amostras nos testes de difusão e concentração inibitória mínima estão dispostos na Tabela 3.

\section{DISCUSSÃO}

Segundo Lenette et al. (1987) os microrganismos são suscetíveis aos antibióticos controle conforme os halos de inibição desenvolvidos, mas a $P$. areuginosa e $E$. coli demonstraram resistência à cefalotina. A não inibição de crescimento com o controle mostra que o etanol não exerceu influência sobre os resultados da atividade do extrato. O resultado da CIM para o EB indica que os mesmos microrganismos no teste de difusão foram afetados pelo extrato bruto.

Nos resultados desta avaliação preliminar foi demonstrado que ocorreu atividade antibacteriana dos produtos vegetais sobre Streptococcus pyogenes e Staphylococcus aureus. Nenhuma atividade foi observada sobre as outras bactérias testadas por difusão em ágar e foi registrada atividade moderada contra todos os microrganismos no teste de concentração inibitória mínima - CIM para o extrato bruto e fração hexano das cascas de E. velutina.

Considerando a quantidade utilizada, foi indicado pelos resultados maior atividade proporcional para a fração hexano. Os esteróides e triterpenos presentes nas plantas estão concentrados geralmente na fração mais apolar, neste caso a fração hexano, e são conhecidos por diversas atividades de interesse biológico, dentre as quais a atividade antimicrobiana. Para substâncias como o $\beta$ sitosterol, a $\alpha$-amirina e lupeol foi demonstrada atividade 
Tabela 3. Resultados das médias dos halos de inibição (em $\mathrm{mm}$ ) dos ensaios de atividade antibacteriana do EB e FHEX de $E$. velutina sobre espécies bacterianas

\begin{tabular}{|c|c|c|c|c|c|c|c|c|c|}
\hline \multirow[t]{3}{*}{ E. velutina } & \multicolumn{9}{|c|}{ Difusão em ágar - Média do diâmetro dos halos de inibição em mm } \\
\hline & \multirow{2}{*}{ Concentrações } & \multicolumn{7}{|c|}{ Microrganismos } & \\
\hline & & $S a$ & $S p$ & $\mathrm{Se}$ & $P m$ & $\mathrm{~Pa}$ & Kp & $E c$ & \\
\hline & $312,75 \mathrm{mg} / \mathrm{mL}(100,0 \%)$ & 7 & 12 & 0 & 0 & 0 & 0 & 0 & 0 \\
\hline \multirow{3}{*}{ EB } & $156,37 \mathrm{mg} / \mathrm{mL}(50,0 \%)$ & 0 & 9 & 0 & 0 & 0 & 0 & 0 & 0 \\
\hline & $78,19 \mathrm{mg} / \mathrm{mL}(25,0 \%)$ & 0 & 7 & 0 & 0 & 0 & 0 & 0 & 0 \\
\hline & $39,10 \mathrm{mg} / \mathrm{mL}(12.5 \%)$ & 0 & 0 & 0 & 0 & 0 & 0 & 0 & 0 \\
\hline \multirow{4}{*}{$\overline{\text { FHEX }}$} & $200 \mathrm{mg} / \mathrm{mL}(100,0 \%)$ & 7 & 13 & 0 & 0 & 0 & 0 & 0 & 0 \\
\hline & $100 \mathrm{mg} / \mathrm{mL}(50,0 \%)$ & 0 & 0 & 0 & 0 & 0 & 0 & 0 & 0 \\
\hline & $50 \mathrm{mg} / \mathrm{mL}(25,0 \%)$ & 0 & 0 & 0 & 0 & 0 & 0 & 0 & 0 \\
\hline & $25 \mathrm{mg} / \mathrm{mL}(12.5 \%)$ & 0 & 0 & 0 & 0 & 0 & 0 & 0 & 0 \\
\hline \multicolumn{2}{|c|}{ Controle Cloranfenicol $(30 \mu \mathrm{g} / \mathrm{mL})$} & 34 & 35 & 38 & 28 & 30 & 30 & 33 & 36 \\
\hline \multicolumn{2}{|c|}{ Controle Cefalotina $(30 \mu \mathrm{g} / \mathrm{mL})$} & 50 & 45 & 40 & 11 & 0 & 26 & 0 & 29 \\
\hline \multicolumn{2}{|c|}{ Controle dos Microorganismos } & + & + & + & + & + & + & + & + \\
\hline \multicolumn{2}{|c|}{ Controle do etanol } & 0 & 0 & 0 & 0 & 0 & 0 & 0 & 0 \\
\hline \multirow{3}{*}{\multicolumn{2}{|c|}{ EB }} & \multicolumn{8}{|c|}{ Concentração Inibitória Mínima $(\mathrm{mg} / \mathrm{mL})$} \\
\hline & & 9,77 & 9,77 & 19,55 & 39,10 & 19,55 & 19,55 & 19,55 & 19,55 \\
\hline & & $(1: 16)$ & $(1: 16)$ & $(1: 8)$ & $(1: 4)$ & $(1: 8)$ & $(1: 8)$ & $(1: 8)$ & $(1: 8)$ \\
\hline
\end{tabular}

Legenda: EB = extrato bruto; FHEX = fração hexano; $S a$ =Staphylococcus aureus; $S p=$ Streptococcus pyogenes; $S e=$ Staphylococcus epidermidis; $P m=$ Proteus mirabilis; $P a=$ Pseudomonas aeruginosa $; \mathrm{Kp}=$ Klebsiella pneumoniae Ec $=$ Escherichia coli; St $=$ Salmonella tiphymurium; + = crescimento dos microrganismos no meio de cultura isento de droga.

contra as bactérias $E$. coli e $S$. aureus, a $\alpha$-amirina $(0,29 \%)$ demonstrou a maior atividade entre os triterpenos presentes na Arnebia hispidissima (Lehm.) DC. contra a E. coli (Singh; Singh, 2003; Jain et al., 2003).

Há de se considerar que o tamanho da zona de inibição de crescimento no teste de difusão é bastante influenciada pela velocidade de difusão das substâncias no ágar (Lenette et al, 1987), sendo assim, é possível que a baixa polaridade dos compostos da fração hexano diminua a velocidade de difusão destes no ágar, gerando um halo de inibição proporcionalmente menor em relação aos antibióticos controle que são polares e ao extrato bruto. Esses resultados colaboram na elucidação preliminar de que os compostos presentes na FHEX estão envolvidos na atividade biológica testada, podendo futuramente direcionar os estudos realizados.

Considerando os resultados dos testes notase que existe potencial antibacteriano e por este motivo novos ensaios estão sendo efetuados visando a melhor exploração desta atividade na fração hexano, nas frações não avaliadas e substâncias isoladas da E. velutina, na busca de novas alternativas terapêuticas que possam servir de subsídio para uma terapêutica racional a partir de fontes naturais brasileiras.

\section{AGRADECIMENTOS}

Ao Dr. Viseldo Ribeiro de Oliveira, Ph.D, da EMBRAPA Semi-Árido, pela obtenção e viabilização da identificação da espécie vegetal e As Ervas Curam Indústria Farmacêutica pelo apoio financeiro.

\section{REFERÊNCIAS}

Amer MA, Shamma M, Freyer AJ 1991. The tetracyclic Erythrina alkaloids. J Nat Prod 54: 329-363.

Carvalho JLS 2001. Contribuição ao estudo fitoquímico $e$ analítico do Nasturtium officinale R. BR., Brassicaceae. Curitiba, 105p. Dissertação de Mestrado - Programa de Pós-Graduação em Ciências Farmacêuticas, Universidade Federal do Paraná.

Cunico MM, Miguel OG, Miguel MD, Kerber VA, Montrucchio DP, Auer CG, Grigoletti Júnior A 2003. Avaliação da atividade antibacteriana de Ottonia martiana Miq., Piperaceae. Rev Ciên Farm 24: 141-145.

Da Cunha EVL, Dias C, Barbosa-Filho JM, Gray AI 1996. Eryvellutinone, an isoflavanone from the stem 
bark of Erythrina vellutina. Phytochemistry 43: 1371-1373.

Dantas MC, Oliveira FS, Bandeira SM, Batista JS, Silva Junior CD, Alves PB, Antoniolli AR, Marchioro M 2004. Central nervous system effects of the crude extract of Erythrina velutina on rodents. $J$ Ethnopharmacol 94: 129-133.

Decker MW, Anderson DJ, Brioni DL, Donelly-Roberts DL, Chae KH, O'neill AB, Piattoni-Kaplan M, Swanson S, Sullivan JP 1995. Erysodine, a competitive antagonist at neuronal nicotinic acetylcholine receptors. European J Pharmacol 280: 79-89.

Dias Filho BP, Nakamura CV, Cortez DAC, Sanches NR, Pessini GL, Holetz FB 2002. Screening of some plants used in the Brazilian folk medicine for the treatment of infectious diseases. Mem Inst Oswaldo Cruz 97: 1027-1031.

EPAMIG - Empresa de Pesquisa Agropecuária de Minas Gerais 1993. O Gênero Erythrina L. no PAMG Herbário da Empresa de Pesquisa Agropecuária de Minas Gerais. Daphne 3: 20-25.

Farmacopéia Brasileira 1988. 4 ed. Parte II, São Paulo, p. v.4.2.3, v. 4.2.4.

Jain SC, Jain R, Singh B 2003. Antimicrobial principles from Arnebia hispidissima. Intern J Pharmacogn 41: 231-233.

Konemann EW, Allen SD, Dowwel Jr VR, Sommers HM 1993. Diagnóstico microbiológico - texto $e$ atlas colorido. 2.ed. São Paulo: Medicina Panamericana Editora do Brasil Ltda.

Lenette EH, Balows A, Hausler WJ, Shadomy HJ 1987. Manual de microbiologia clinica. 4. ed. Buenos Aires: Editorial Medica Panamericana.

Lorenzi H 1992. Árvores brasileiras: manual de identificaçãoe cultivo de plantas arbóreas nativas do Brasil. São Paulo: Editora Plantarum.

Lorenzi H, Matos FJA 2002. Plantas medicinais no Brasil: nativas e exóticas cultivadas. São Paulo: Instituto Plantarum de Estudos da Flora Ltda.

Miguel MD, Miguel OG 2004. Desenvolvimento de fitoterápicos. 2ed. São Paulo: Robe Editorial.

Rabelo LA, Agra MF, Da Cunha EVL, Silva MS, Barbosa Filho JM 2001. Homohesperetin and phaseollidin from Erythrina velutina. Biochem Syst Ecol 29: 543-544.

Romeiro R da S 2001. Métodos em bacteriologia de plantas. Viçosa: Ed. UFV.

Singh B, Singh S 2003. Antimicrobial activity of terpenoids from Trichodesma amplexicaule Roth. Phytother Res 17: 814-816.

Telikepalli H, Gollapudi SR, Keshavarz-Shokri A, Velazquez L, Sandamann RA, Veliz EZ, Jagannadha Rao KV, Madhavi AS, Mitscher LA 1990. Isoflavonoids and a cinnamyl phenol from root extracts of Erythrina variegata. Phytochemistry 29: 2005-2007.
Vasconcelos SMM, Rebouças Oliveira G, Mohana de Carvalho M, Rodrigues ACP, Rocha Silveira E, Fonteles MFM, Florenço Sousa FC, Barros Viana GS 2003. Antinociceptive activities of the hydroalcoholic extracts from Erytrhrina velutina and Erythrina mulungu in mice. Biol Pharm Bull 26: $946-949$. 